\title{
Lecturers' Thinking Preferences and Learners' Individual Differences Based on the Whole Brain Model: A Case of Solusi University, Zimbabwe
}

\author{
Christinah Dlamini, PhD \\ Manager, Centre for Teaching Excellence and Pedagogy in E- Learning \\ Solusi University, Zimbabwe. \\ "Corresponding author: dlaminic@solusi.ac.zw
}

\begin{abstract}
Quality of learning outcome is the primary goal of higher education. University lecturers should be equipped with andragogic skills to enhance learning. At the exemplar institution, 10 lecturers, aged below 50, were not trained to teach in higher education. Recurring evaluation comments, from Bachelor and Master of Education students highlighted lecturers' poor teaching methods. This study therefore, adopted Whole Brain model by Herrmann (1996) to enhance the quality of teaching practice. The model is comprehensive in facilitating innovative teaching techniques and enhancing learning. It encourages lecturers to be aware of their thinking style preferences in order to design learning opportunities that factor in learners' diverse learning differences (De Boer, Du Toit, Scheepers and Bothm, 2011). Herrmann Brain Dominance Instrument (HBDI) (a survey questionnaire) was used to collect quantitative data while face to face interviews gathered qualitative information. $\mathrm{HBDI}^{\circ}$ data was computed into participants' thinking preference profiles. Deductive thematic approach was used for qualitative data analysis and results showed diversity in thinking styles among the participants. The majority confirmed their understanding of the model and its diagnosis of thinking preferences. The HBDI proved to be a valid, reliable measure of human mental preferences. The research recommends the participants to fruitfully use the HBDI in their teaching endeavors. Seminars on learning style flexibility are recommended as part of professional development. Finally, institutions of higher learning can subscribe to the Whole Brain ${ }^{\circ}$ Group and have their workers and students complete the HBDI so that they become aware of their preferences for teaching-learning benefits.
\end{abstract}

Key words: Professional development, Whole Brain model, thinking preference, Herrmann Brain Dominance Instrument ${ }^{\circ}$

\section{Introduction}

Knowledge of teaching skills improves to a great extent as a result of professional development which enables lecturers to provide high quality learning opportunities for students. University lecturers' professionalism is shaped inter alia by andragogic skills which help deliver the content efficiently and engage students in effective learning. To remain abreast of diverse student learning expectations, lecturers should therefore upgrade themselves with innovative ways to improve their teaching practice (Mkonto, 2015, Cekiso, 2015). Whole Brain thinking model is a major innovative method in addressing learners' individual learning preferences. Through the model, lecturers become cognizant of various thinking and learning styles hence answering the question, What are the lecturers' thinking preferences? Learning styles are common likings to process information in different or diverse ways, (Knowles, Holton and Swanson, 2015). Whole Brain teaching means presenting a lesson to students, using a variety of learning opportunities (Cekiso, 2011; Hill, Tomkinson, Hiley and Dobson, 2014). Whole Brain teaching keeps students' learning styles or learning preferences in the lecturer's mind when developing course outlines/syllabuses, lectures, assignments, tests, 
examinations and interactive activities, thus embracing the diverse learning preferences of students (Mkonto, 2015; Du Toit, 2016). This study was timely and significant in transforming educators' teaching practice. Whole Brain ${ }^{\circledR}$ Model therefore, shows a connection of a lecturer's thinking and his style of teaching (Herrmann International, 2017; Du Toit, 2016) hence, answering question: How are lecturers' thinking preferences connected with their style of teaching?

William Ned Herrmann, an American physicist, both author and creative researcher, described as the brain dominance father, learnt of the pioneering brain research on the split brain of Roger Sperry, Paul MacLean, Joseph Bogen and Michael Gazzanaga in the 1980's. The four researchers perceived that the brain had four distinctive and specialized structures. Herrmann was motivated and hence carried out several tests and surveys to determine the pioneers' findings. He learned that the brain dominance is derived from hemispheric dominancy of the right and the left hemispheres (Cave, 2003). He described these two hemispheres as the cerebral that separates into cerebral left and the cerebral right and the limbic system, which is situated at the bottom of each of the cerebral hemispheres. The left limbic system influences planning activities while the right system is the basis of emotional activity. The cerebral and the limbic hemispheres give a four-way split-up, graphically forming quadrants. Each quadrant best describes the specialization of the part of the brain (Herrmann, (1982). These quadrants explain how the 'creativity of human brain is unleashed' (De Boer, Du Toit, Scheepers and Bothma 2013, p. 3). Herrmann then came out with the Whole Brain model.

The Whole Brain model is therefore an innovative teaching strategy that can be used to demonstrate the change from traditional education to a transformative approach to teaching and learning that is characterized by different interactive activities and student engagement (Dobozy, 2012). Further, when used in the classroom, the Whole Brain model improves relationships of lecturers and students and thereby creating collaborative learning (May and May 2012 p.3). De Boer, et al., (2011, p.77) affirm that the "Whole Brain" Thinking model caters for diversity and that various thinking styles can lead to more effective learning." Mkonto (2015) acknowledges that using Whole Brain teaching creates opportunities for lecturers to consider their students' preferred learning styles, thereby developing students' other skills and competencies. Furthermore, Du Toit (2013) argues that Whole Brain model forms part of the scholarship of teaching and learning in that it enriches teaching, assessment, curriculum development and research supervision. Kirstein and Kunz (2016) affirm that when lecturers understand the different learning styles of students, they can be able to design differentiated learning opportunities that accommodate all learning styles across a diverse student groups.

Pushkar (2015, p. 25) posits that "Teaching to children and teaching to adults are two different things. Children are ready to learn anything that comes to them but it is not true in the case of adult education." To authenticate this observation, the evaluation of lecturers' teaching and assessment at the exemplar institutions in the past five years has shown that most lecturers lacked innovation and creativity in teaching and in the assessment of students' work. Recurring comments, especially from B.Ed. and M.Ed. students were on poor teaching methods (Solusi University Faculty Evaluations, 2011-2016). This has resulted in compromised lecture delivery which needs to be rectified if progressive teaching is to be achieved. The Whole Brain model was therefore adopted in this research in an attempt to transform teaching practice by lecturers (Ozgen, Tataroglu and Askan 2011; De Boer, Du Toit, Scheepers and Bothma, 2013). This research therefore, aimed at creating awareness among lecturers of the significance of understanding and accommodating thinking preferences in the lecture rooms.

\section{Related Literature and Studies}

Literature on the significance of professional development in higher education emphasises the need for lecturers to be visionary practitioners who understand how students in the $21^{\text {st }}$ century learn. Race (2015) defines the role of the lecturer as intricate as he/she should be well-informed of the tenet of the lecture room which has changed tremendously beyond recognition. Students now claim high quality in the ways their learning and assessment are implemented. Joseph (2013) affirms Race's view by echoing that Twenty-first century learners are quite different from the students of fifteen or twenty years ago. Since students do not all learn the same thing on the same day in the same way, educators are increasingly faced with the 
challenge of knowing students well enough to cater for their varying needs in the classroom. Brew (2010) posits that the business of teaching and learning in universities should focus on the diversity of students' ways of learning. The Whole Brain model presents such scholarship.

\section{What constitutes Whole Brain ${ }^{\circledR}$ Thinking}

This section describes what constitutes Whole Brain ${ }^{\circledR}$ thinking. Herrmann (1995) describes the Whole Brain model as one that illustrates that everyone has a preferred way of thinking and this style of thinking has an effect on the way one takes in and processes information. Ozgen, Tataroglu and Askan (2011) recommend Whole Brain model to lecturers who wish to understand the learning processes better and attain individualization in education by considering student individual learning differences/styles. Du Toit (2016) expands on learning styles and presents a comprehensive model of various learning opportunities lecturers can employ in facilitating learning. He explores the diverse students' preferred ways of learning as well as their avoidances. Literature on learning style preferences proves that identifying students' learning preferences could help lecturers choose suitable learning opportunities (Cekiso, 2011).

Fringe (2013) carried out research in Mozambique and used the Whole Brain model in the development of lecturers' professional practice. He observed patterns of reflection linked to the Whole Brain model as lecturers reflected mostly in their preferred brain quadrants. In Zimbabwe, Phuthi (2012) acknowledged the Whole Brain model and HBD I as widely used and ideal in understanding student diversity. De Boer, Du Toit, Scheepers and Bothma (2013, p. 26) encourage the use of Whole Brain $^{\circledR}$ model in teaching by asserting the following:

Our knowledge of the brain and its inherent uniqueness indicated that a student has unique learning experiences, preferences and avoidances that are different from those of other students. If we are serious about improving the quality of learning, we need to be aware of this.

For a better illustration of the whole concept of Whole Brain thinking, figure 1 provides a summary of how the two hemispheres previously discussed split into the two modes; the cerebral and the limbic systems. The figure also shows how the four quadrants are formed (Source: www.bing.com/images).

\section{Whole Brain Model ${ }^{\odot}$}

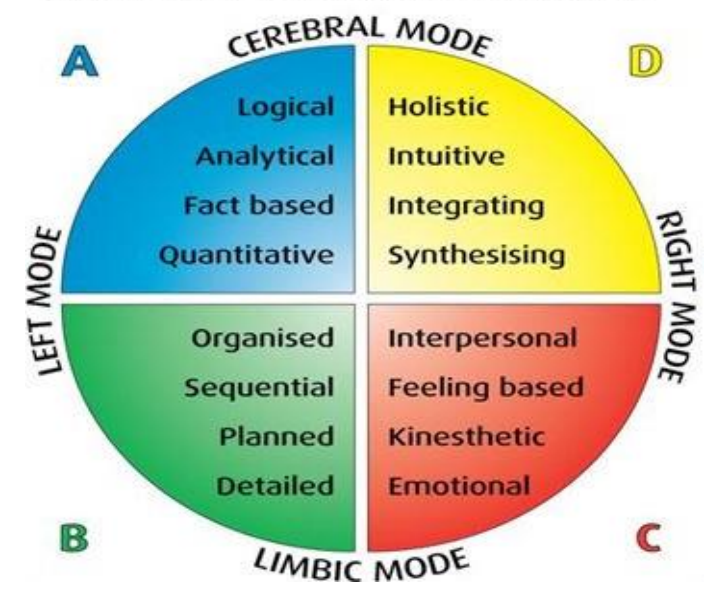

Figure1: The cerebral and limbic systems of Herrmann's whole Brain model

The first, upper left cerebral is referred to as quadrant $A$ - represented by the blue colour and the second, lower left limbic is quadrant B- represented by the green colour. The first lower right limbic is referred to as quadrant $\mathrm{C}$ - represented by the red colour and the upper right cerebral is referred to as quadrant $D$ - represented by the yellow colour. The four quadrants are "interconnected clusters of specialized mental processing modes that function together and iteratively making up a Whole Brain in which one or more parts become naturally dominant" (Fringe 2013, p. 65). Each quadrant represents distinctive purposes, describing the ways one prefers to study, outlining typical professions, dressing habits and the like. The four quadrants are further elaborated by showing how different students would prefer to learn in the classroom. (See figure 2 for illustration).

For a lecturer to accommodate all the learning preferences of students he/she would have to adopt a teaching style that reflects all the thinking styles of students, becoming very flexible and balanced in the way that he/she facilitates learning (Herrmann, 1996). Determining the learning styles of the students serve as a benchmark for the lecturer to adapt the style of facilitating learning as one's learning style directly influences one's style of facilitating learning. Knowing one's thinking 
preferences and avoidances would assist the lecturer to vary the learning opportunities in order to accommodate those students who do not share their thinking style, thereby moving out of one's comfort zone.

\begin{tabular}{|c|c|}
\hline $\begin{array}{l}\text { A Learns by: } \\
\text { - Acquiring and quantifying facts } \\
\text { - Analysis and logic } \\
\text { - Thinking through ideas } \\
\text { - Building cases } \\
\text { - Forming theories }\end{array}$ & $\begin{array}{l}\text { Learns by: } \\
\text { - Taking initiative } \\
\text { - Exploring hidden possibilities } \\
\text { - Relying on intuition } \\
\text { - Constructing concepts } \\
\text { - Synthesising content }\end{array}$ \\
\hline $\begin{array}{l}\text { B Learns by: } \\
\text { - Organising and structuring } \\
\text { content } \\
\text { - Evaluating and testing theories } \\
\text { - Practice }\end{array}$ & $\begin{array}{l}\text { C Learns by: } \\
\text { - Listening and sharing ideas } \\
\text { - Integrating experiences with self } \\
\text { - Moving and feeling } \\
\text { - Emotional involvement } \\
\text { - Harmonising with content }\end{array}$ \\
\hline
\end{tabular}

Figure2: Learning styles of the four quadrants (Source: Herrmann, 1996, 154)

\section{The Herrmann Brain Dominance Instrument ${ }^{\oplus}$} The Herrmann Brain Dominance Instrument ${ }^{\circ}\left(\mathrm{HBDI}^{\circ}\right)$ is a survey questionnaire that shows how one prefers to think. It is an online self-assessment questionnaire comprising 120 items that quantify mental (thinking) preferences for each of the four thinking styles (De Boer et al., 2013). The responses evaluate the strength of the four quadrants and relate each to one another. This results in a four quadrant profile that displays the degree of preference for each of the four quadrants (Herrmann International, 2018). For each profile there are three sets of numbers placed in order of the quadrants, A, B, C and D. The preference code is indicated by the number 1 with a numerical value of 67 to 99 , termed strong preference or primary; code 2 with a numerical value of 34 to 66 is a general or secondary or intermediate preference that shows neither preference nor avoidance; code 3 indicates tertiary preference, which symbolizes low preference or a lack of interest in that quadrant's thinking, or avoidance with a numerical value of 0 to 33. In the $\mathrm{HBDI}^{\circ}$ questionnaire there are 24 pairs of adjectives designed to show how one prefers to think. The 24 points are distributed among the four quadrants. The highest score has a maximum of 12 , which typically reveals the thinking style favored in pressured or stressful situations that may differ from the preferred style. The distribution of responses into the $A, B, C$ and $D$ quadrants, arranged in descending order could indicate a less preferred quadrant becoming more dominant or a generally preferred one receding into the background. The profile score is the total score allocated to the four quadrants, based on individuals' responses to the $\mathrm{HBDI}^{\circ}$ survey form (Herrmann International, 2018; De Boer et al., 2013). This information is better illustrated in the section on descriptive data analysis. What is significant to note about the $\mathrm{HBDI}^{\circ}$ profiles is that there is no profile that is good, bad, wrong or right. Every profile has some positive qualities and some challenges related to it as well (Herrmann Group, 2004; Herrmann International, 2017; 2018).

\section{Herrmann's thinking preference profiles}

There are four types of profile: The first is the single dominant which takes different patterns, such as 1222. This profile has a strong preference for Quadrant A. The second is 2122, with a strong preference for Quadrant B. The third is 2212 with a strong preference for the $C$ quadrant and finally, 2221 with a strong preference for the $D$ quadrant (De Boer et al., 2013; Du Toit, 2013). Following, the single dominant, is a double dominant profile which has three characteristics: the first is the double dominant profile - left or right; the second is double dominant profile - upper and lower, which is also 
known as double dominant in the same hemisphere. The last double dominant profile is the double dominant diagonal. This is a diamond-shaped family of a profile crossing the diagonals from either $B$ to $D$ or $\mathrm{A}$ to $\mathrm{C}$. The pattern for a double dominant is 1122. This shows a strong preference for quadrants $A$ and $B$. The second is 2211 , that shows preference for $C$ and $D$ and the last is 1212 with a strong preference for $A$ and $C$. The third dominance is the triple dominant profile. It has the following variations: 2111, showing strong preferences for quadrants $B, C$ and $D ; 1121$ showing preference for A, B and D and finally 1112, showing strong preference for A, B and C. (Herrmann Group, 2004). The last but not the least profile is the quadruple (quad) dominance. This profile shows a strong preference for all four quadrants. Very few people have such dominance. The people with this dominance are said to be balanced because they integrate all four quadrants. The individuals have the ability to function effectively in groups or work conditions that need flexibility (Herrmann International, 2017).

It can be concluded that the brain dominance or preferred modes of understanding relate strongly to what one prefers and how one prefers to go about learning (Herrmann, 1995). Herrmann (1996) avers that the brain dominance's thinking preferences of a person influences that person's learning style. If one intensely prefers one mode, one will reject another; this is termed avoidance (ibid). Therefore Whole Brain model encourages a person to balance the four quadrants to have a holistic approach to life. To the education practitioner, this means designing learning opportunities that accommodate all the four quadrants, hence accommodating students' diverse learning preferences. When a lecturer facilitates learning in a manner that addresses all the thinking styles presented by the four quadrants of the model, the lecturer facilitates Whole Brain ${ }^{\oplus}$ learning.

\section{Research Methodology}

The research used a mixed method approach. The $\mathrm{HBDI}^{\oplus}$ questionnaire was used to determine the thinking preferences of the 10 participants while face to face structured interview was used to authenticate the results of the $\mathrm{HBDI}^{\oplus}$. A questionnaire is an instrument with a list of questions that are answered by the respondents. The instrument is used to collect data that may be answered in the absence of the researcher. It is disseminated to several people and it is often easy to analyse (Cohen, Mahon and Morrison 2011; Kumar, 2014). Hendricks (2013) further defines a structured interview as a prepared list of specific questions in which content and procedures are organized before the interview. It is meant to guide the process of getting specific or intended information from participants or respondents. A structured interview also provides opportunities for the participants to describe the situation in their own terms, thereby revealing the many features of an experience that has an effect on the issue investigated (Hendricks, 2013).

\section{Population and Sampling}

A sample is a sub-group of the population the researcher is interested in (Kumar, 2014). The study employed typical case sampling. Typical case sampling is a type of purposive sampling that "includes the most typical cases of the group or population under study" (Cohen et al., 2011, p. 157).

Table 1 Biographical information of participants

\begin{tabular}{ccl}
\hline Participant & Age & \multicolumn{1}{c}{ Qualification } \\
\hline P 1 & 47 & Master of Education, Secondary \\
P2 & 43 & Master of Arts, Theology \\
P3 & 39 & Master of Business Administration \\
P4 & 45 & Master of Business Administration \\
P5 & 33 & Master of Business Administration \\
P6 & 46 & Master of Education, Secondary \\
P7 & 31 & Master of Business Administration \\
P8 & 45 & Master of Education, Secondary \\
P9 & 33 & Master of Arts, Public Relations \\
P10 & 31 & Master of Arts, Mathematics \\
\hline
\end{tabular}

Ten lecturers teaching at the exemplar institution in Zimbabwe were the typical group selected for the particular characteristic of being inexperienced in teaching in higher education. Hendricks (2013) adds to the description that samples in practitioner studies may not be large enough for statistical analysis to be fitting. In this regard the selected lecturers fitted the purpose of this study in that they were not trained to teach in higher education institutions and with their ages ranging from 30 to 49 years. According to the researcher, this age group was energetic enough to acquire innovative teaching skills and present scholarly contributions to the body of knowledge in higher education. Table 1 gives the biographic information of the 10 participants. The 10 participants were coded with the consonant ' $P$ ' for participant and they were designed according to their surnames' alphabetical order. Since the lecturers participating were 10 in 
number, numbers from 1 to 10 were therefore assigned to each participant.

All the participants were of the age of 49 and below. Of the 10 participants, 7 (the majority), did not have a teaching qualification Only 3 (P1, P6 and P8) had Master of Education degree in secondary education. Therefore, none had a qualification for teaching in higher education. The fact that none had a certificate or diploma for teaching in higher education authenticates the inexperience variable that formed part of the gap for this study.

\section{Validity and Reliability}

Validity is based on determining whether the results are accurate (Lincolin and Guba 1985). Reliability according to Cohen et al (2011, p. 199) "is concerned with precision and accuracy..." Being aware of the probability of loss or change of data during its transfer from the interviewee to the interviewer, the researcher used the feedback evaluation data that is defined by Lincoln and Guba, (1985) as involving returning transcribed written scripts to respective participants for confirmation of information given in the interview meetings. linterviews were transcribed verbatim by an expert in qualitative research and participants were asked to read through the transcriptions and verify by signing them off if the transcriptions were correct.

The $\mathrm{HBDI}^{\oplus}$ survey questionnaire was designed by experts; these are the Herrmann International group of researchers. The $\mathrm{HBDI}^{\circledR}$ is testified by the Coffield report of 2004 and is commended as one of the validated models in education and training (De Boer et al., 2011). Herrmann International (2017) guarantees the validity of the instrument by reporting that validation studies have been conducted for more than 35 years. May and May (2012) confirm the effectiveness of the Whole Brain model, in that it is valuable in education since it fosters creative thinking and problem solving skills. Du Toit (2013) confirms the validity of the instrument as having good face, factorial and construct validity. The good face validity is linked to the fact that the $\mathrm{HBDI}^{\oplus}$ relates to one's life experience hence it is as an instrument with authentic quality.

\section{Ethical Considerations}

Permission to carry out the research was granted by the University Administration Board (ADBORD) of the exemplar institution. After being granted permission to carry out this research, certain guidelines were put in place to protect the participants from being harmed or deceived. To comply with the people in authority, permission from academic deans was sought since participants were from the five faculties. All the participants were informed regarding what their participation entailed. They had to agree that they were willing to participate and that they had been assured that the confidentiality of their responses and their participation would be guaranteed (Hendricks, 2013). Participants were told that participation was completely voluntary. Consent letters were then signed by the participants.

\section{Analysis and Results}

The following is a detailed presentation of the $\mathrm{HBDI}{ }^{\circledR}$ profiles of the 10 participants. Data is presented on profile charts which display the breakdown of the four quadrants that resulted from the responses to the 120 items of the questionnaire that was filled.
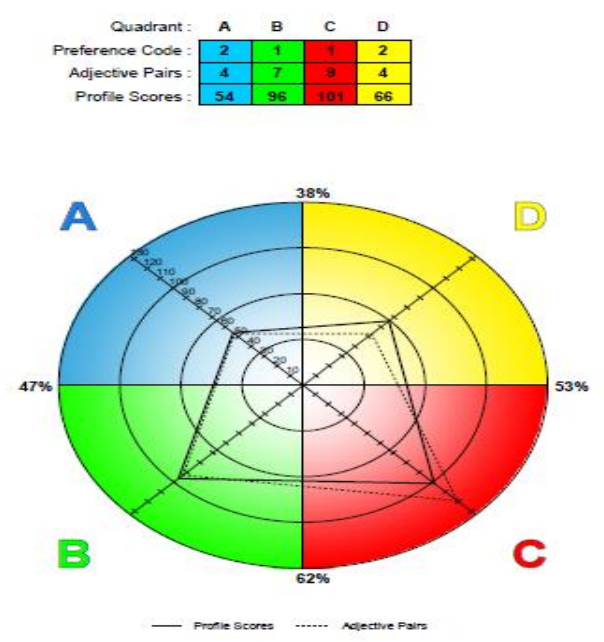

Figure 3: P1's double dominant profile: 2112

Participants' thinking preferences were plotted according to their responses. Each participant's thinking preference profile is presented in a table that summarizes the scores which are then plotted on a chart under four research questions:

Research Question One: What are the thinking preferences of the lecturers under investigation?

Double dominant profile: Lower B and Lower C

Figure 3 shows a double dominant left and right profile for $\mathrm{P} 1$ that indicates a strong preference for Lower quadrants B and C and less preference for Upper quadrants $A$ and $D$. In the study this participant was the only one with this type of dominance. 
Double dominant profile: Upper A and Lower B In the study we had P5 and P10 with this kind of double dominance. They had a preference code of 1122. They had strong preferences for the upper $A$ and lower B quadrants and less preference for Lower $C$ and Upper D quadrants. Although the two participants shared the double dominance profile of 1122, they had different patterns and different scoring percentages in each quadrant. These variations authenticate the Whole Brain model that emphasises human diversity in thinking. Both had strong preferences in the left hemisphere.
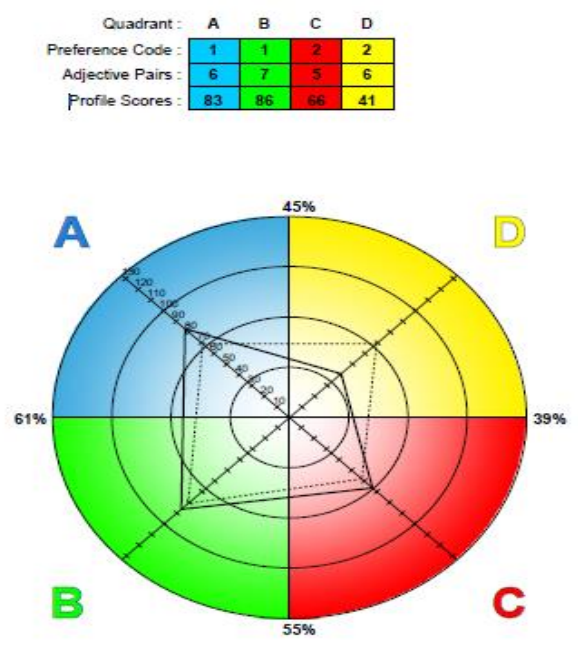

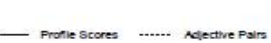
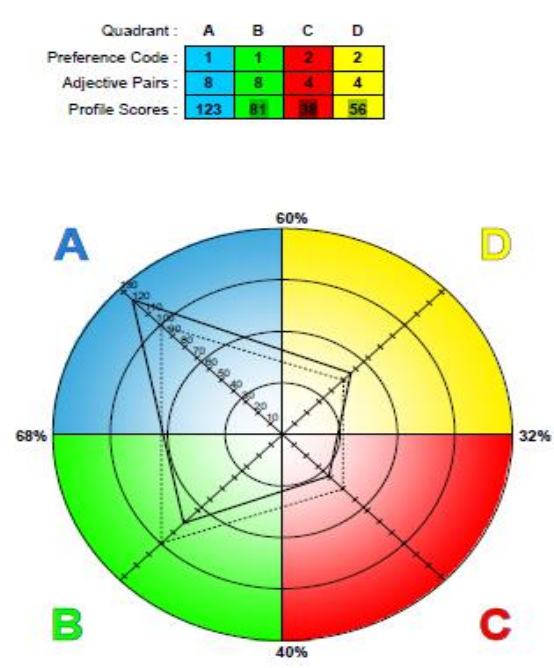

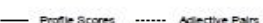

Figure 3: P5 and P10's double dominant profiles: 1122

Double dominant profile in the same hemisphere

Figure 4 shows $\mathrm{PG}^{\prime}$ s double dominance profile in the same hemisphere indicating strong preference in the Upper D and Lower $C$ quadrants and less preference in Upper A and Lower B quadrants: 1122. The profile is different from P5 and P10 double dominant in that P6 is strong in the right hemisphere.
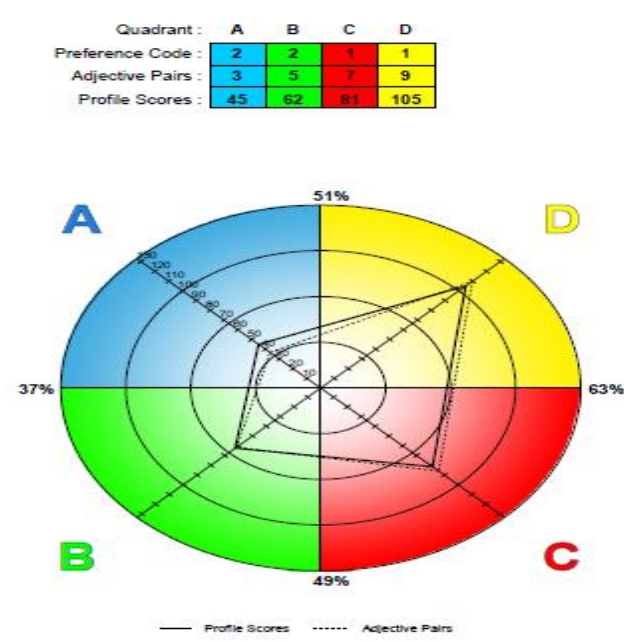

Figure 4: $P 6$ 's double dominance profile: 2211

\section{Double dominant diagonal profile}

The last double dominant profile is the double dominant diagonal. This is a diamond-shaped family of a profile crossing the diagonals from either $B$ to $D$ or $A$ to $C$. This is the most common of all four dominances as is shown by the high percentage; however, in the study we did not have this type of dominance.

\section{Triple dominant profile}

The next dominance is the triple dominant profile. It has the following variations: 2111, 1121 and 1112. These allow the individuals to move among their three dominant modes somewhat seamlessly, looking at all of the perspectives before making decisions (Herrmann Group, 2004). Five of the participants had a triple dominant profile with the following variations: 2111 (P2; P3 and P9); P8 (1112) P7 (1121). Although the three participants shared the triple dominance of 2111 they have different patterns and different scoring percentages in each quadrant, again authenticating the Whole Brain model's emphasis on human diversity in thinking. To a lecturer, this implies careful planning of learning opportunities as there are no students who would prefer learning in the same way, even though they share a similar quadrant. Figure 5 shows P2, P3 and P9's triple dominance profile indicating strong preference for Lower $B, C$ and Upper D quadrants and less preference for Upper $A$ quadrant. 

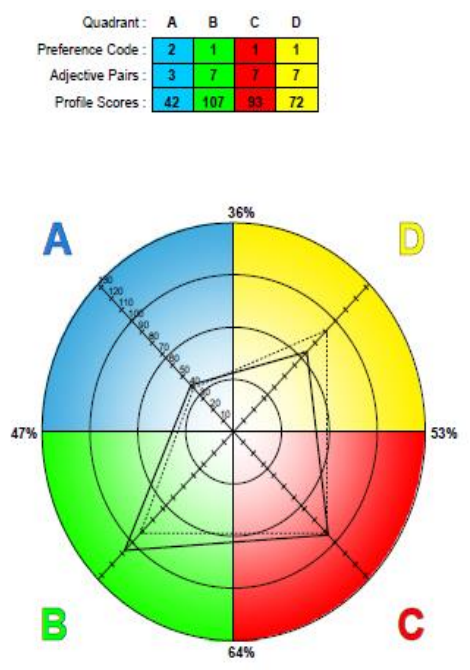

-
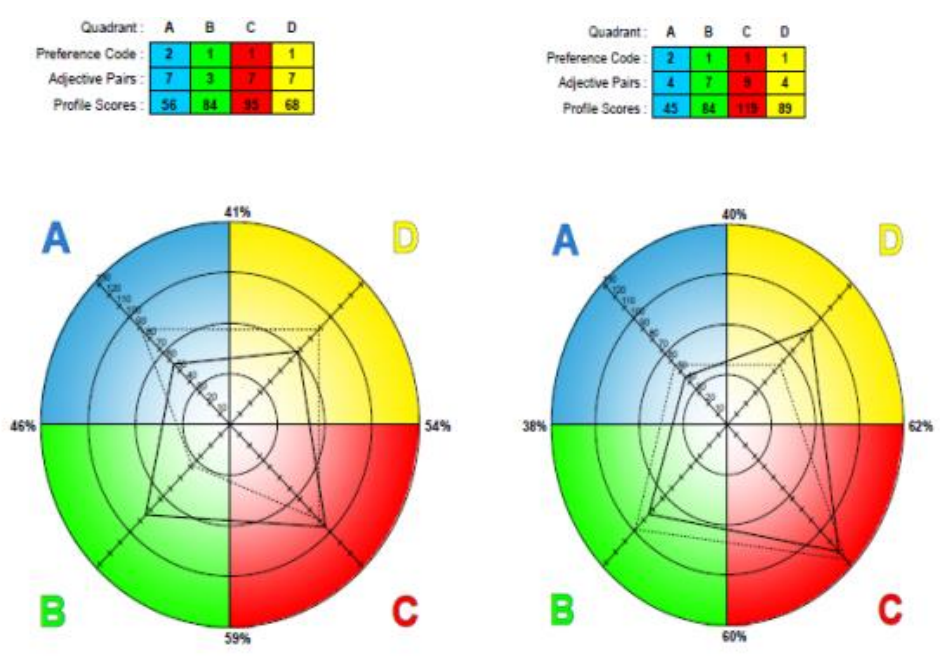

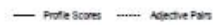

Figure 5: LP2, P3 P9's triple dominance profile: 2111

On figure 6 is another variation of a triple dominance profile for $\mathrm{P7}$ indicating a strong preferece for Upper A, D and Lower B quadrants and less preference for Lower $C$ quadrant.
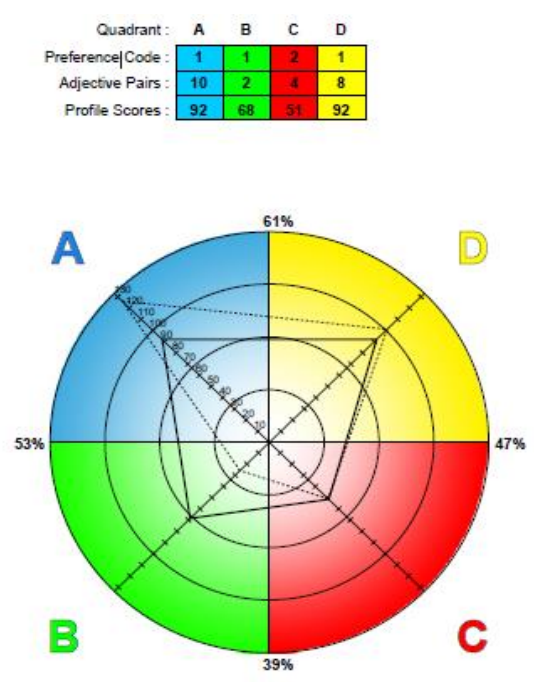

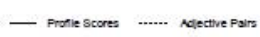

Figure 6: LP7's triple dominance profile: 1211

Figure 7 shows $\mathrm{P} 8$ 's triple dominant profile with a strong preference for Lower B, C and Upper A quadrants and less preference for Upper $D$ quadrant.

\section{Quadruple dominant profile}

The last but not the least profile is the quadruple (quad) dominance. This profile shows a strong preference for all four quadrants and such profiles have a $3 \%$ of the population of people diagnosed by Herrmann. This means that very few people have such dominance. The people with this dominance are said to be balanced because they integrate all four quadrants. The individuals have the ability to function effectively in groups or work conditions that need flexibility (Herrmann International, 2017). In the study, P4 belonged to this profile. The participant related well to all the respondents. Figure 8 shows P4's quadruple dominance profile indicating strong preference for all four quadrants.
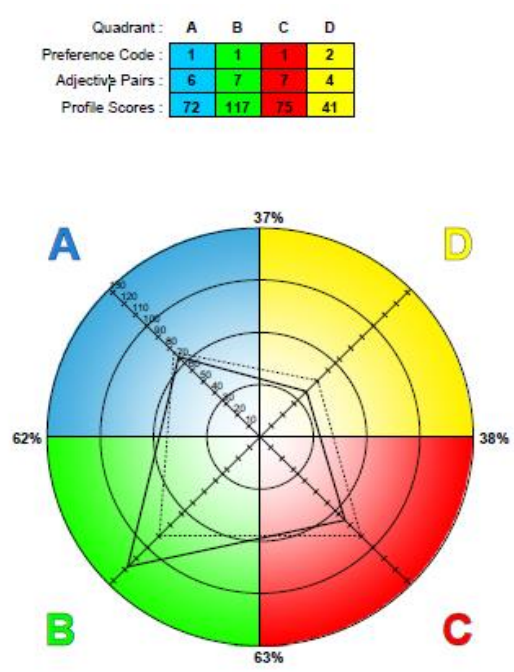

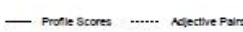

Figure 7: P8's tripple dominanc: 1112

\section{Qualitative Data Analysis}

Thematic analysis can be done inductively or deductively. Deductive thematic analysis provides a 
thorough analysis of the data. This approach is particularly useful when one has specific research questions that already identify the main themes or categories used to group the data and then looked for similarities and differences. Cohen et al. (2011, p. 539) echo that this analysis is very useful "as it draws together all the relevant data for the exact issue of concern to the researcher, and preserves the coherence of the material". It returns the reader to the driving concerns of the research. The following structured interview questions were asked to solicit participants' views about the $\mathrm{HBDI}^{\oplus}$ diagnosis, their understanding of the diagnosis and how they were going to improve their teaching practice. The analysis was summed up in Table 2 .

Table 2: Research questions, interview questions and themes

\begin{tabular}{|c|c|c|}
\hline Research Question & Interview Question & Theme (s) \\
\hline What constitutes Whole & Briefly explain what you understand the & Participants' perception of the \\
\hline \multirow[t]{2}{*}{ Brain thinking? } & Whole Brain Model to be. & Whole Brain Theory \\
\hline & $\begin{array}{l}\text { Comment on Whole Brain }{ }^{\circledR} \text { Model and its } \\
\text { connection with student learning }\end{array}$ & $\begin{array}{l}\text { Whole Brain Model and its } \\
\text { connection with student learning }\end{array}$ \\
\hline $\begin{array}{l}\text { What are the thinking } \\
\text { preferences of the }\end{array}$ & $\begin{array}{l}\text { Do you mind sharing your thinking } \\
\text { preferences as determined by the } \mathrm{HBDI} \text { ? }\end{array}$ & $\begin{array}{l}\text { Participants' thinking preferences as } \\
\text { determined by the HBDI }\end{array}$ \\
\hline
\end{tabular}

participants?

Did the instrument reflect your correct thinking preferences?

\section{Research Question Two: What constitutes Whole Brain thinking?}

\section{Theme 1: Participants' perceptions of Whole Brain ${ }^{\oplus}$ model}

The participants' responses showed their understanding of Whole Brain model. The responses reflected that participants realised that the brain functions as a whole and that the four quadrants represented different thinking and learning styles. Participants found out that the Whole Brain model helped them understand that people are different; therefore they think or learn in a variety of ways, depending on how they prefer doing things. The model was instrumental as it helped them understand students' diverse learning preferences. Knowing their preferences helped them plan to accommodate students' learning styles in their teaching and assessment. De Boer et al. (2011) postulate that implementing the Whole Brain ${ }^{\oplus}$ model in tertiary level studies enhances the quality of lecturers' facilitation of learning as they will be conscious of their peculiar thinking preferences and the implication these have for their teaching practice.

Recurring answers from the interviews revealed that the Whole Brain ${ }^{\oplus}$ model concerns itself, inter alia, with human diversity; how people think differently and how they prefer doing certain things in certain ways as is symbolized in the four different quadrants $A, B, C$, and D.
Research Question Three: How is Whole Brain Model connected with student learning?

Theme 2: Whole Brain ${ }^{\oplus}$ model's connection with student learning

Participants' interview responses reflected that Whole Brain ${ }^{\oplus}$ model was connected with student learning as it involved understanding and accommodating students' diverse learning preferences. Participants learnt that the model helped lecturers to understand their diversity in thinking and teaching styles. Therefore, students in like manner were different and would want learn differently. This awareness of diversity would guide planning learning opportunities that would accommodate the diverse learning styles of students. Once the learning opportunities addressed the students' learning preferences or needs, learning would be enjoyable and meaningful (Cekisi, 2011; Du Toit, 2014; Herrmann International, 2017; 2018; Mkonto, 2015).

Research Question Four: Did the instrument reflect your correct thinking preferences?

\section{Theme 3: Participants' thinking preferences as determined by the $\mathrm{HBDI}^{\circledR}$}

Of the 10 lecturer participants in the study, 8 affirmed the correct diagnosis of their thinking preferences by means of the $\mathrm{HBDI}^{\circledR}$. These were: $\mathrm{P} 1$, P2, P4, P5, P6, P7, P8 and LP9. The diagnosis concurred with the evaluation given by Herrmann in the following statement: "One of the strengths of the $\mathrm{HBDI}^{\circledR}$ is its ability to measure any specialization 
specifically" (Herrmann, 1982, 70). Participant 3, for instance, said it reflected his thinking preferences fairly, while P2 said it partially did. When asked to describe their profile scores, 5 managed to describe them correctly. These were: P1, P5, P6, P7 and P10. They were also able to explain what each score meant. The other five could not really state the exact numerical scores; for instance, P2 said his was 2112 instead of 2111; P3 stated that he was a 211 person, instead of 2111; P4 said he was profile 4, and P8 just said that she loved planning and presenting her work sequentially, while P9 mentioned that she was a rational person who was expressive and creative. Though the participants did not clearly state the exact statistics on their profiles, further probing showed that they knew what their profiles meant. For instance, P2 (2111) stated that he was not mathematically inclined in the $A$ quadrant where he scored a 2 (secondary preference). He was more interested in the arts; he was talkative and loved music (C and D quadrants). The conclusion given then was that the participants generally knew their profiles; it was the new terminology that might have confused them.

\section{Conclusions and Recommendations}

This section comes up with conclusions that come from results and then gives recommendations to stakeholders:

\section{Conclusions}

The study's focus on lecturers' thinking preferences to enhance learners' individual difference using the Whole Brain "was realised in that the participants were cognizant of the need to understand themselves in order to understand the diverse student learning preferences (Herrmann Group, 2004). The intention of motivating lecturers to move out of their comfort zones, thereby accommodating the quadrants that were secondary to them, was emphasized (Du Toit, 2013). The Herrmann Brain Dominance Instrument (HBDI $)$ proved to be a valid, reliable measure of human mental preferences. Participants learnt that in order to know their students well and to produce innovative learning opportunities for students, they needed to know themselves first. Whole Brain Thinking gave lecturer the knowledge to improve teaching performance, communication and effectiveness in assessing students' work, both as individuals and as a collective. It encouraged them to take a comprehensive view of their practice.

\section{Recommendations}

Researchers recommend the participants to fruitfully use the $\mathrm{HBDI}^{\circ}$ results and general knowledge they gained in the study for their teaching endeavors. Also, the Whole Brain concepts of facilitating learning should be adopted by institutions of higher learning in across Zimbabwe. Seminars on learning style flexibility and how lecturers can accommodate diverse thinking styles are also recommended as part of improving teaching strategies. Finally, institutions can subscribe to the Whole Brain Group and have their workers and students complete the $\mathrm{HBDI}^{\circ}$ so that they become aware of their preferences. When people are aware of diverse thinking preferences, they learn to accommodate one another and improve their communication skills too. When Students understand their preferences they will be able to select their fields of specialization and choose their jobs appropriately. For instance, the logical one (A) would take legal or managerial or accounting occupations, while the organizer (B) would prefer supervisory/administrative fields. The interpersonal (C) would take the supporting/service or education careers while the creative (D) would prefer entrepreneurial and artistic fields of occupation (Fringe, 2013; De Boer et al., 2013; Herrmann International, 2017; 2018).

\section{References}

Brew, A. (2010). Transforming academic practice through scholarship. International Journal for Academic Development, 15(2), 105-116.

Cave, C. (2003). The Four Quadrant Model and the Brain: Ned Herrman's Whole Brain model. Retrieved 7 12, 2019, from www.Kheper.net/topics/intelligence/Herrm ann.htm.

Cekiso, M. P. (2011). Profiling learning style preference of first year university students: Implications for course designs and instruction. South Journal of Higher Education, 25(7), 1288-1309.

Cekiso, M. Arendas, J. \& Mkabile. B. (2015). Exploring the Learning Style Preferences used by Accounting Students in a University of Technology in South Africa. Journal of Social Sciences, 43(3), 237-244. 
Coffield, F. Moseley, D. Hall, E. \& Ecclestone, K. (2004). Learning Styles and Pedagogy in Post - 16 Learning: A systematic and Critical Review. London: Learning and Skills Research Centre.

Cohen, L. Manion, L., \& Morrison, K. (2011). Research methods in education ( $7^{\text {th }}$ ed.). London: Routledge..

De Boer, A. L., Bothma, T., \& Du Toit, P. H. (2011). Enhancing information literacy through the application of whole brain strategies. Libri, $61,67-75$..

De Boer, A. L., Du Toit, P. H., Sheepers, M. D., \& Bothma, T. J. (2013). Whole brain learning in higher education:Practice-based evidence. Oxford: Chandos Publishing.

Dobozy, E. (2012 ). Learning in higher education symposium: A new professional development model of univesrsity educators. Issues in Educational Research, 22(3), 228-245.

Du Toit, P. (2013 ). Social Transformation starts with self: An autobiographical perspective on thinking style preferences of an educator. South African Journal of Education, 33(4), 112.

Du Toit, P. (2014). Framing higher education as a means of addressing the expectations of society using different frames (of mind). South African Journal of Higher Education, 28(3), 673-1132.

Du Toit, P. (2016). Action research as innovative means to self-study: A quest for thinking out of my box. OER Africa/SAIDE Convening. Nairobi: du-toit-p-action-researchinnovative-means-self-study.pdf-Adobe Reader.

Fringe, J. J. (2013). Promoting critical reflection for academic professional development in higher education.PhD Thesis. South Africa: University of Pretoria.
Hendricks, C. (2013). Improving schools through action research: A Reflective Approach (3rd Ed). Boston: Pearson.

Herrmann Group. (2004). The HBDI ${ }^{\circledR}$ Team Profile Guide. Retrieved from www.herrmannsolutions.com

Herrmann International. (2017). HBDI $^{\circledR}$ \& Whole Brain $^{\circledR} \quad$ Thinking. Retrieved from www.HerrmannSolutions.com

Herrmann International. (2018). Herrmann Brain ${ }^{\circledR}$ Dominance Instrument, $\mathrm{HBDI}^{\circledR}$. Profile Package.

Herrmann, N. (1982). The Creative Brain II: A Revisit with Ned Herrmann. Training and Development Journal, 75-88. Retrieved November 16, 2017

Herrmann, N. (1995). The Creative Brain, $\left(2^{\text {nd }} \mathrm{ed}\right)$ ). (USA: Quebecor Printing Book Group).

Herrmann, N. (1996). The whole brain business book. New York: MacGraw- Hill..

Hill, F., Tomkinson, B., Hiley, A \& Dobson, H. (2014). Learning Style Prefernces: An Examination of Differences Among Students with Different Backgrounds. Innovations in Education and Teaching International Print. Retrieved from https://www.research. manchester.au.uk.

Kirstein, M. \& Kunz, R. (2016). A Whole Brain Learning Approach to an undergraduaate Auditing Initiative- An Exploratory Study. pp. 1-18. doi:DDI:10.1108/MEDAR-02-204-0029

Knowles, M. S., Holton III, E. F., \& Swanson, R. A. (2015). The adult learner:The definitive classic in adult education and human resource development ( $8^{\text {th }}$ ed.). Burlington: Elsevier..

Kumar, R. (2014). Research methodology a step by step guide for beginners. London: SAGE. 
Lincolin, Y.S.\& Guba, E.G. (1985). Naturalistic Inquiry. Beverly Hills,CA:: Sage.

May, C. H. and May, P. H. (2002). Case Study: Spotling on Learning Using HDBI Assessment to Improve Learning Process, Quality and Outcomes at Yale College, Wales Herrmann International.

Mkonto, N. (2015). Students' Voices in Learning Style Assessment: The Innovative Learning Experiences Too (ILE). Journal Studies in Education, 6(2), 181-198..

Ozgen, K.,Tataroglu, B., \& Alkan, H. (2011). An examination of brain dominance and learning styles of pre-service mathematics teachers. Procedia Social and Behavioral Sciences, 15, 743-750. Retrieved from www.sciencedirect.com
Phuthi, N. (2012). Enhansing quality academic practice through intergrated industry based learning PhD Unpublished Thesis. University of Pretoria, South Africa.

Pushkar, P. (2015). Role of teacher in higher education. International Journal of Education and Information Studies, 5(1), 2530. Retrieved from http://www.ripublication.com

Race, P. (2015). A Practical Guide to Assessment, Learning and Teaching. New York: Routledge.

Solusi University. (2011-2016). Faculty Evaluations. Bulawayo: Solusi University. 